\title{
Helping Babies Breathe and its effects on intrapartum-related stillbirths and neonatal mortality in low-resource settings: a systematic review
}

\author{
Jorien M D Versantvoort, ${ }^{1}$ Mirjam Y Kleinhout, ${ }^{2}$ Henrietta D L Ockhuijsen, ${ }^{1,3}$ \\ Kitty Bloemenkamp, ${ }^{4}$ Willem B de Vries, ${ }^{2}$ Agnes van den Hoogen ${ }^{1,2}$
}

${ }^{1}$ Clinical Health Science,

Utrecht University, Utrecht, The Netherlands

${ }^{2}$ Department of Neonatology, Birth Center Wilhelmina's Children Hospital, Division Women and Baby, University Medical Center Utrecht, Utrecht, The Netherlands ${ }^{3}$ Department of Reproductive Medicine and Gynaecology, University Medical Centre Utrecht, Utrecht, The Netherlands

${ }^{4}$ Department of Obstetrics Birth Center Wilhelmina's Children Hospital, Division Women and Baby, University Medical Center Utrecht, Utrecht, The Netherlands

\section{Correspondence to}

Agnes van den Hoogen, Intensive Care Neonatology, Wilhelmina's Children's Hospita University Medical Centre Utrecht, Lundlaan 6, Utrecht 3508 AB, The Netherlands; ahoogen@umcutrecht.nl

JMDV and MYK contributed equally.

Received 2 October 2018 Revised 10 June 2019 Accepted 13 June 2019 Published Online First 2019

\section{Check for updates}

(C) Author(s) (or their employer(s)) 2020. No commercial re-use. See rights and permissions. Published by BMJ.

To cite: Versantvoort JMD, Kleinhout MY

Ockhuiisen HDL, et al.

Arch Dis Child

2020:105:127-133.

\section{ABSTRACT}

Background An important factor in worldwide neonatal mortality is the deficiency in neonatal resuscitation skills among trained professionals. 'Helping Babies Breathe' (HBB) is a simulationbased training course designed to train healthcare professionals in the initial steps of neonatal resuscitation in low-resource areas. The aim of this systematic review is to provide an overview of the available evidence regarding intrapartum-related stillbirths and neonatal mortality related to the HBB training and resuscitation method.

Data sources Cochrane, CINAHL, Embase, PubMed and Scopus.

Study eligibility criteria Conducted in low-resource settings focusing on the effects of HBB on intrapartumrelated stillbirths and neonatal mortality.

Study appraisal Included studies were reviewed independently by two researchers in terms of methodological quality.

Data extraction Data were extracted by two independent reviewers and crosschecked by one additional reviewer.

Results Seven studies were included in this systematic review; the selected studies included a total of 230.797 neonates. Significant decreases were found after the implementation of HBB in one of two studies describing perinatal mortality ( $n=25108$, rate ratio (RR) 0.75 ; $p<0.001)$, four out of six studies related to intrapartumrelated stillbirths ( $n=125.720$, RR $0.31-0.76)$, in four out of five studies focusing on 1 day neonatal mortality $(n=111.289$, RR 0.37-0.67), and one out of three studies regarding 7 day neonatal mortality $(n=4.390$, RR 0.32). No changes were seen in late neonatal mortality after HBB training and resuscitation method.

Limitations Included studies in were predominantly of moderate quality, therefore no strong recommendations can be made.

Conclusions and implications of key findings Due to the heterogeneous quality of the studies, this systematic review showed moderate evidence for a decrease in intrapartum-related stillbirth and 1-day neonatal mortality rate after implementing the 'Helping Babies Breathe' training and resuscitation method. Further research is required to address the effects of simulation-based team training on morbidity and mortality beyond the initial neonatal period.

PROSPERO registration number CRD42018081141.

\section{What is already known?}

- 'Helping Babies Breathe' (HBB) is a simulationbased training method designed to train healthcare professionals in resource limited areas.

- A determining factor in neonatal mortality is the worldwide deficiency in trained professionals in neonatal resuscitation.

\section{What this study adds?}

- Evidence regarding neonatal mortality in relation to the HBB method and recuscitation method showed a reduction in intrapartumrelated stillbirths and neonatal mortality.

- HBB is a simple and low-cost intervention that can be helpful in training healthcare professionals in neonatal resuscitation.

\section{INTRODUCTION}

Globally, approximately 2.6 million neonates die each year within the first month of life. ${ }^{1}$ Of these deaths, 98\% occur in low-resource countries where $50 \%-70 \%$ of neonatal deaths occur on the day of birth.

In 2000, world leaders committed to reducing neonatal mortality by two thirds by 2015 in the Millennium Development Goals. Although a decline of 36 to 19 neonatal deaths per 1000 live births was seen, a two-thirds reduction was not reached. ${ }^{2}$

In the Sustainable Developmental Goals, world leaders of all United Nation countries set their new aim in 2015 that global neonatal mortality should be at least as low as 12 per 1000 live births by $2030^{1}$.

An important factor in neonatal mortality is the worldwide lack of professionals trained in neonatal resuscitation. ${ }^{3}$ Most deliveries in low-resource settings are attended by one person who cares for the mother and baby. Many birth attendants lack formal education or training; they have learnt their skills from other birth attendants or by delivering babies themselves. ${ }^{45}$

Each year, approximately 10 million babies do not start breathing by themselves and would die within minutes without help. ${ }^{6}$ The first minute of 
life, also called 'the golden minute,' is crucial for preventing neonatal mortality. ${ }^{7-10}$

The need to improve neonatal care and resuscitation is most urgent in low-resource settings. ${ }^{2}$ Research shows an improvement in preventing intrapartum-related stillbirths and neonatal mortality by introducing neonatal resuscitation training programs. ${ }^{611}$ These training programmes consist of simulationbased training that has benefits in clinical practice. ${ }^{6}$

Research has shown that a proportion of stillbirths are in fact non-resuscitated neonates that consequently die. ${ }^{12} 13$

Adequate classification tools are often lacking, which can lead to erroneous estimations of stillbirths and neonatal mortality. The Global Implementation Task Force of the American Academy of Pediatrics (AAP) has-in collaboration with many partners-developed the so-called 'Helping Babies Breathe' (HBB) training. ${ }^{414} \mathrm{HBB}$ is a simulation-based training method designed to train healthcare professionals in low-resource settings in postnatal resuscitation and care. ${ }^{314}$

Various papers have evaluated the educational effects of the HBB training method. HBB has resulted in improved neonatal resuscitation knowledge and skills ${ }^{75-19}$

Maintaining a sufficient level of neonatal resuscitation skills requires repeated practice and testing. ${ }^{15} 16$ In a recent review of Dol et al, a Helping Babies Survive programme was evaluated in terms of neonatal outcome and healthcare provider knowledge and skills as the main outcome. ${ }^{20}$ The HBB module is one of three modules in Helping Babies Survive. The aim of this systematic review is to present an overview of the available evidence regarding intrapartum-related stillbirths and neonatal mortality in relation to the HBB training and resuscitation method as an intervention on its own.

\section{METHODS}

Design

In this systematic review, the association between the HBB method, intrapartum-related stillbirths and neonatal mortality was reviewed following the principles of the Preferred Reporting Items for Systematic Reviews (PRISMA) statement. ${ }^{21}$

The clinical heterogeneity of included studies meant that the meta-analysis method would have been inappropriate. Therefore, the results of this systematic review will be described in a narrative manner.

\section{Information sources}

A literature search included articles published until 7 November 2017 and an update of the search was performed 24 August 2018. To include all studies that were possibly relevant to the research question, the following databases were used: Cochrane, CINAHL, Embase, PubMed and Scopus.

\section{Search strategy}

Entry terms were formulated based on the research question 'Neonatal Mortality (MeSH)' that included intrapartum-related stillbirth and 'Helping Babies Breathe.' The terms 'low-income countries', 'low-middle-income countries' or 'low-resource settings' were not added to the entry terms because HBB is a specific training method in these settinngs. The Appendix includes an overview of the entry terms and the search strategy.

\section{Inclusion and exclusion criteria}

All studies conducted in low-resource settings focusing on the association between $\mathrm{HBB}$ and intrapartum-related stillbirths and/or neonatal mortality were included. Different subcategories
Table 1 Categories of mortality

\begin{tabular}{|c|c|}
\hline \multicolumn{2}{|c|}{ Categories of mortality } \\
\hline $\begin{array}{l}\text { Perinatal } \\
\text { mortality }\end{array}$ & $\begin{array}{l}\text { All deaths in the first week after birth, including } \\
\text { intrapartum-related stillbirths. }{ }^{26} 27\end{array}$ \\
\hline $\begin{array}{l}\text { Intrapartum- } \\
\text { related stillbirths }\end{array}$ & $\begin{array}{l}\text { Birth of a fetus with an Apgar score of } 0 \text { by } 1 \text { and } 5 \text { min, with no } \\
\text { signs of maceration and suspected dying during labour. }\end{array}$ \\
\hline 1-day mortality & All deaths of live-born infants within 24 hours after birth. ${ }^{24-28}$ \\
\hline 7-day mortality & All deaths of live-born infants within in the first week of life. ${ }^{262829}$ \\
\hline $\begin{array}{l}\text { 7-28-day } \\
\text { mortality }\end{array}$ & $\begin{array}{l}\text { Late mortality, all deaths of live born infants between the first } \\
\text { week and first month of life. }\end{array}$ \\
\hline 28-day mortality & All deaths of live-born infants within in the first month of life. ${ }^{1028}$ \\
\hline
\end{tabular}

were used to clarify intrapartum-related stillbirths and neonatal mortality, as presented in table 1 . Pilot studies and study protocols were excluded from this systematic review. To find all available evidence, no limitations were placed on the search.

\section{Study selection}

All studies resulting from searches in the databases were screened for inclusion and exclusion criteria. Two independent reviewers read the full text of selected studies. Records of screening and study selection are presented as a flowchart in figure 1; debates on the inclusion or exclusion of studies were discussed with a third researcher. All included studies were published in English.

\section{Data extraction}

Data were extracted by two independent reviewers and crosschecked by one additional reviewer. Results were entered in a data extraction form. Data extracted from selected studies included: design, study duration, sample, setting, study outcomes and results. If there were missing data, researchers contacted the responsible author to request it.

In the results, neonatal mortality was divided into defined subcategories: perinatal mortality, intrapartum-related stillbirths, 1-day mortality, 7-day mortality, 7-28-day mortality and 28-day mortality.

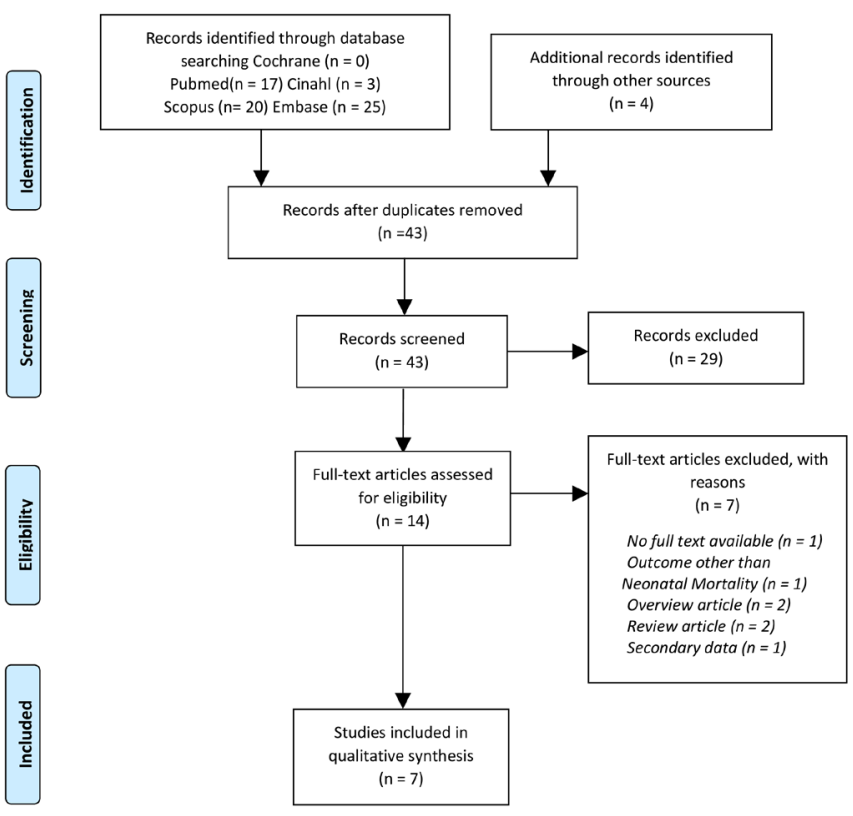

Figure 1 PRISMA flowchart study selection. PRISMA, Preferred Reporting Items for Systematic Reviews. 


\section{Synthesis}

Data about the results in intrapartum-related stillbirths, neonatal mortality and the performance of the HBB training method were obtained from included studies and a rate ratio (RR) was calculated; when $\mathrm{RR}<1$, there was a decrease in the mortality rate after $\mathrm{HBB}$ training compared with before HBB training. Best-evidence synthesis according to Proper et al was used to assess the overall value of the results found in the literature and to draw appropriate conclusions. ${ }^{22}$ The assessed quality of the included studies was taken into account. Evidence could be stated at three levels: strong evidence in which results were consistent between two or more high-quality studies; moderate evidence where there were consistent results either in one high-quality with at least one lowquality study or in multiple low-quality studies. When only one study was available or there were inconsistent results in multiple studies, the evidence was considered insufficient.

Results were considered consistent when at least $75 \%$ of the studies showed the same effects which was defined according to the significance $(\mathrm{p}<0.05) .^{22}$

\section{Methodological quality}

The included studies were reviewed by two researchers independently on methodological quality according to the McMaster critical review form for quantitative studies, ${ }^{23}$ which was chosen for its potential in using one scale for several quantitative designs, which contributed to the studies' comparability. The review form consisted of 15 items including the risk of bias and each point was assessed as,$++/-$ or - . + meant fulfilled, +/- meant partially fulfilled and - meant unfulfilled. Only items scored as + generated one point. For this systematic review, the cut-off points were defined by the authors as they were not given in the McMaster critical review form for quantitative studies. Examples from the literature using this critical appraisal tool were taken into account to set cut-off points. A score of 13-15 was considered high quality, a score of 9-12 was moderate quality and a score of $\leq 8$ was low quality. Similarities and differences were discussed until consensus was achieved. When consensus was not reached, disagreements were resolved by discussing these issues with a third researcher.

\section{RESULTS}

Study selection

In total, 79 articles were found. After removing duplicates, 43 articles were screened for title and abstract to assess the relevance of the research question. Twenty-nine articles were excluded in this phase. The full texts of the 14 remaining articles were read full text. Subsequently, another seven articles were excluded; the full text of one article was not available even though the first author was contacted several times. One article focused on outcome measures other than neonatal mortality, two articles had no scientific content, one article was a review with new information but no extractable data, one article was an earlier published systematic review and one article used data from earlier research that had already been included.

Based on the research question and the inclusion and exclusion criteria, seven studies in total were included in this systematic review. No randomised controlled trials were available. The selected studies were cohort studies with pre-post design where data were collected before and after the HBB training method was implemented. The data collection duration was in the range 11-26 months.

The selected studies were published in English between 2012 and 2018. Two studies were conducted in Tanzania, ${ }^{24} 25$ one in
India, ${ }^{10}$ one in both India and Kenya, ${ }^{26}$ two in $\mathrm{Nepal}^{2728}$ and one in Sudan. ${ }^{29}$ The selected studies included 230797 participants.

HBB training was performed differently in the selected studies e.g duration of training and follow-up was unidentical. . ${ }^{27}$ Table 2 gives an overview of the included studies' characteristics.

\section{Methodological quality}

Based on the McMaster critical review form for quantitative studies, all included studies showed a total score of $8-13$. These were considered low (one study) to moderate (five studies) and high (one study) quality. One study did not describe the method of HBB training. Furthermore, contamination and cointervention were not addressed in most included studies. Table 3 presents an overview of the selected studies' methodological quality.

\section{Results of individual studies shown by subcategory}

Where numbers and CI were available, they were presented and rate ratio (RR) was calculated. Table 4 presents an overview of the results for neonatal mortality.

\section{Perinatal mortality}

Two studies focused on perinatal mortality, Bellad et al trained $\mathrm{HBB}$ in India and Kenya at primary, secondary and tertiary centres, refreshed the training after 6 months and measured mortality 12 months before and after training. They found no significant difference in their perinatal mortality rate. ${ }^{26} \mathrm{Kc}$ et al trained a cohort of hospital workers at a tertiary hospital in Nepal and implemented an extensive quality improvement cycle. They found a significant difference in perinatal deaths before and after implementation: perinatal mortality rate decreased from $30.9 / 1000$ births to $23.3 / 1000$ births (RR 0.75; $\mathrm{p}<0.001$ ). ${ }^{27}$

\section{Intrapartum-related stillbirths}

Six of the studies addressed intrapartum-related stillbirths. ${ }^{10}$ 24-27 29 The results of Bellad et al were not significant. ${ }^{26}$ Mduma et al trained a cohort of hospital workers at a rural referral centre in Tanzania and set up a 'low-impact highfrequency' refresher training system. The results of this study were not significant.

Results were significant in four of the studies, even though there were differences between individual studies. ${ }^{10} 24252729$ Arabi et al showed the results of training in rural community training centres in Sudan with weekly peer-to-peer practice. Their stillbirth rate (SBR) results went from 10.5 to $3.3 / 1000$ births (RR 0.31; $\mathrm{p}=0.003) .{ }^{29}$ Goudar et al trained a cohort of health workers at primary health centres and district and urban hospitals in India that included one refresher training. Their SBR went from 17.2 to $9.2 / 1000$ births (RR 0.53 ; 95\% CI 0.37 to $0.78 ; \mathrm{p} \leq 0.001) .{ }^{10} \mathrm{Kc}$ et al described a change in intrapartumrelated stillbirths from 9.0 to $3.2 / 1000$ (RR 0.36; 95\% CI 0.32 to $0.66 ; \mathrm{p}<0.001) .{ }^{27}$ Msemo et al trained a cohort of health workers in referral, district and regional hospitals in Tanzania; they described a difference in intrapartum-related stillbirths before and after implementation of HBB from 19.0 to $14.4 / 1000$ (RR $0.76 ; 95 \%$ CI 0.64 to $0.90 ; \mathrm{p}=0.001) .{ }^{25}$

\section{One-day neonatal mortality}

The studies that focused on the 1-day neonatal mortality rate (NMR) showed a variable outcome after the implementation of $\mathrm{HBB} ;{ }^{24-28}$ the results of Bellad et al were not significant. ${ }^{26}$ Four studies showed significant results, although there were some differences. Kc et al described a difference in the 1-day NMR before and after implementation from 5.2 to $1.9 / 1000$ of live 
Table 2 Study characteristics

\begin{tabular}{|c|c|c|c|c|}
\hline \multicolumn{5}{|c|}{ Study characteristics } \\
\hline $\begin{array}{l}\text { Author (year) } \\
\text { Country }\end{array}$ & Design & $\begin{array}{l}\text { Duration of the } \\
\text { study }\end{array}$ & Sample ( $\mathrm{n}=$ neonates) and setting & Intervention \\
\hline $\begin{array}{l}\text { Arabi et } a l^{29}(2018) \\
\text { Sudan }\end{array}$ & Cohort & $\begin{array}{l}24 \text { months } \\
\text { Pre: } 6 \text { months } \\
\text { Post: } 18 \text { months }\end{array}$ & $\begin{array}{l}\mathrm{n}=4390 \\
\text { Pre: } \mathrm{n}=1350 \\
\text { Post: } \mathrm{n}=4030 \\
\text { In rural community medical centres. }\end{array}$ & HBB and weekly peer to peer resuscitation skills practice. \\
\hline $\begin{array}{l}\text { Bellad et } a^{26} \\
(2015) \\
\text { India and Kenya }\end{array}$ & Cohort & $\begin{array}{l}24 \text { months } \\
\text { Pre: } 12 \text { months } \\
\text { Post: } 12 \text { months }\end{array}$ & $\begin{array}{l}\mathrm{n}=70704 \\
\text { Pre: } \mathrm{n}=35595 \\
\text { Post: } \mathrm{n}=35109 \\
\text { In primary, secondary and tertiary } \\
\text { facilities. }\end{array}$ & HBB: Initial training and refresher training after 6 months. \\
\hline $\begin{array}{l}\text { Goudar et al } \\
\text { (2012) } \\
\text { India }\end{array}$ & Cohort & $\begin{array}{l}11 \text { months } \\
\text { Pre: } 5 \text { months } \\
\text { Post: } 6 \text { months }\end{array}$ & $\begin{array}{l}\mathrm{n}=9598 \\
\text { Pre: } \mathrm{n}=4187 \\
\text { Post: } \mathrm{n}=5411 \\
\text { In primary health centres, district and } \\
\text { urban hospitals. }\end{array}$ & $\begin{array}{l}\text { HBB: Initial training ( } 1 \text { day course) and refresher training if } \\
\text { desired within an average of } 230 \text { days. }\end{array}$ \\
\hline $\begin{array}{l}\text { Kc et al }{ }^{27}(2016) \\
\text { Nepal }\end{array}$ & $\begin{array}{l}\text { Cohort, including a } \\
\text { nested case- control }\end{array}$ & $\begin{array}{l}15 \text { months } \\
\text { Pre: } 6 \text { months } \\
\text { Post: } 9 \text { months }\end{array}$ & $\begin{array}{l}\mathrm{n}=25108 \\
\text { Pre: } \mathrm{n}=9588 \\
\text { Post: } \mathrm{n}=15520 \\
\text { In a tertiary hospital. }\end{array}$ & $\begin{array}{l}\text { HBB-Quality Improvement Cycle: } \\
\text { Two-day training, daily skill checks, self-evaluation after every } \\
\text { delivery, peer review after every resuscitation, weekly review and } \\
\text { reflection meetings } \\
\text { Refresher training after } 6 \text { months. }\end{array}$ \\
\hline $\begin{array}{l}\text { Mduma et } a l^{24} \\
\text { (2015) } \\
\text { Tanzania }\end{array}$ & Cohort & $\begin{array}{l}24 \text { months } \\
\text { Pre: } 12 \text { months } \\
\text { Post: } 12 \text { months }\end{array}$ & $\begin{array}{l}\mathrm{n}=9708 \\
\text { Pre: } \mathrm{n}=4894 \\
\text { Post: } \mathrm{n}=4814 \\
\text { In a rural referral hospital. }\end{array}$ & $\begin{array}{l}\text { HBB: One day training for all care providers working on the } \\
\text { labour ward, monthly training sessions of } 40 \text { min, weekly training } \\
\text { sessions for a short HBB training of } 3 \text { min and practice when time } \\
\text { permitted. }\end{array}$ \\
\hline $\begin{array}{l}\text { Msemo et } a l^{25} \\
\text { (2013) } \\
\text { Tanzania }\end{array}$ & Cohort & $\begin{array}{l}26 \text { months } \\
\text { Pre: } 2 \text { months } \\
\text { Post: } 24 \text { months }\end{array}$ & $\begin{array}{l}\mathrm{n}=86624 \\
\text { Pre: } \mathrm{n}=8124 \\
\text { Post: } \mathrm{n}=78500 \\
\text { In referral, regional and district hospitals. }\end{array}$ & $\begin{array}{l}\text { HBB: One day training and refresher training. Every shift: } \\
\text { document application of basic skills including Face Mask } \\
\text { Ventilation. }\end{array}$ \\
\hline $\begin{array}{l}\text { Wrammert et a/ } 28 \\
\text { (2017) } \\
\text { Nepal }\end{array}$ & Cohort & $\begin{array}{l}15 \text { months } \\
\text { Pre: } 6 \text { months } \\
\text { Post: } 9 \text { months }\end{array}$ & $\begin{array}{l}n=24.665 \\
\text { Pre: } n=9.390 \\
\text { Post: } n=15.275 \\
\text { In a tertiary hospital. }\end{array}$ & $\begin{array}{l}\text { HBB: all } 137 \text { staff trained, no description on method/duration/ } \\
\text { refreshment. }\end{array}$ \\
\hline
\end{tabular}

births (RR 0.37; p<0.001). ${ }^{27}$ Mduma et al showed a drop in the 1-day NMR from 11.1 to $7.2 / 1000$ (RR $0.65 ; 95 \%$ CI 0.41 to $0.98 ; \mathrm{p}=0.04) .{ }^{24}$ Msemo et al showed that 1 -day mortality decreased from 13.4 to $7.1 / 1000$ (RR 0.53 ; 95\% CI 0.43 to 0.65 ; $\mathrm{p}<0.0001){ }^{25}$ Early perinatal mortality (intrapartum-related stillbirths+1-day mortality) dropped from 32.2/ to $21.6 / 1000$ (RR $0.67 ; 95 \%$ CI 0.59 to 0.76 ; p <0.0001). ${ }^{25}$

Furthermore, the proportion of birth-asphyxia-related deaths was studied and decreased from $86.0 \%$ to $31.0 \%$ after implementing HBB (RR 0.36 ; 95\% CI 0.31 to $0.40 ; \mathrm{p}<0.0001$ ).

Finally, Wrammert et al trained a cohort of health workers at a tertiary hospital in Nepal without describing refresher training schedules and showed a decrease in 1-day mortality from 5.5 to $1.9 / 1000$ live births (RR $0.35 ; \mathrm{p}<0.01) .^{28}$

\section{Seven-day neonatal mortality}

Mortality among live-born infants who died in their first week of life was studied by Arabi et al, Bellad et al and Wrammert et al. ${ }^{262829}$ Only Arabi et al's results showed a significant decrease in 7-day neonatal mortality of from 13.5 to 4.3/1000 (RR 0.32, $\mathrm{p}=0.001) .{ }^{29}$ In Bellad et al, the 7-day NMR went from 13.0 to $14.0 / 1000(\mathrm{RR} 1.08,95 \% \mathrm{CI}-5.45$ to $-2.64 ; \mathrm{p}=0.49) .{ }^{26}$ Wrammert et al found no significant results. ${ }^{28}$

\section{7-28-day mortality}

Wrammert et al studied late neonatal mortality (7-28 days), but the results in this study were not significant. ${ }^{28}$

\section{8-day mortality}

The number of live-born infants who died in their first month of life was studied by Goudar et al and Wrammert et al. ${ }^{10} 28$ They found no significant changes after implementing their HBB training programmes.

\section{Synthesis of results}

All included studies were assessed in terms of quality.

One study of moderate quality found a significant decrease in perinatal mortality. ${ }^{27}$ However, according to Proper et al, one study is not enough to draw strong conclusions.

Of the six studies that focused on intrapartum-related stillbirths, four showed a significant decrease. ${ }^{10242527}$ The results of these studies suggest the same effect. According to Proper et al, this indicates that there is moderate evidence to support the association between a decrease in the intrapartum-related stillbirths and $\mathrm{HBB} .^{22}$

Five studies addressed the 1-day NMR, of which four found significant results. ${ }^{2425} 2728$ The 1-day NMR decreased, although the numbers differed. Mduma and Msemo in Sub-Saharan Africa showed a larger mortality rate than Kc and Wrammert in Nepal. Despite that, the results suggest the same effect this indicates that there is moderate evidence to support the association between a decrease in 1-day NMR and HBB.

Regarding the 7-day NMR, only Arabi et al, which was assessed as high quality, showed a significant decrease. ${ }^{29}$ No significant results were found for 28-day NMR, which also indicates that 
Table 3 Methodological quality of included studies

\begin{tabular}{|c|c|c|c|c|c|c|c|c|}
\hline \multicolumn{9}{|c|}{ McMaster critical review form-quantitative studies } \\
\hline & & $\begin{array}{l}\text { Arabi et } a l^{29} \\
(2018)\end{array}$ & $\begin{array}{l}\text { Bellad et } a l^{26} \\
(2016)\end{array}$ & $\begin{array}{l}\text { Goudar et } a l^{10} \\
(2012)\end{array}$ & $\begin{array}{l}\text { Kc et } a l^{27} \\
(2016)\end{array}$ & $\begin{array}{l}\text { Mduma et } a l^{24} \\
(2015)\end{array}$ & $\begin{array}{l}\text { Msemo et } a l^{25} \\
(2013)\end{array}$ & $\begin{array}{l}\text { Wrammert et } \\
a^{28}(2017)\end{array}$ \\
\hline \multicolumn{2}{|l|}{ Study purpose } & + & + & + & + & + & + & + \\
\hline \multicolumn{2}{|l|}{ Literature } & + & + & + & - & $+1-$ & + & + \\
\hline \multicolumn{2}{|l|}{ Design } & + & + & + & + & + & + & $+1-$ \\
\hline \multirow[t]{2}{*}{ Sample } & Description & + & + & + & + & $+1-$ & + & + \\
\hline & $\begin{array}{l}\text { Sample size } \\
\text { justified }\end{array}$ & - & - & - & + & + & + & $+1-$ \\
\hline \multirow[t]{2}{*}{ Outcomes } & Reliable & + & + & + & + & + & - & $+/-$ \\
\hline & Valid & + & + & + & - & + & - & + \\
\hline \multirow[t]{3}{*}{ Intervention } & Description & + & - & + & + & + & + & - \\
\hline & Contamination & + & - & - & - & + & - & - \\
\hline & Cointervention & + & - & - & - & + & + & - \\
\hline \multirow[t]{4}{*}{ Results } & $\begin{array}{l}\text { In terms of } \\
\text { statistical } \\
\text { significance }\end{array}$ & + & + & + & + & + & + & + \\
\hline & $\begin{array}{l}\text { Analysis } \\
\text { appropriate }\end{array}$ & + & + & + & + & + & + & + \\
\hline & $\begin{array}{l}\text { Clinical } \\
\text { importance }\end{array}$ & + & + & + & + & + & + & + \\
\hline & $\begin{array}{l}\text { Drop-outs } \\
\text { reported }\end{array}$ & - & + & + & - & - & - & - \\
\hline \multicolumn{2}{|c|}{ Conclusions and implications } & + & + & + & + & + & + & + \\
\hline \multicolumn{2}{|l|}{ Score } & $13 / 15$ & $11 / 15$ & $12 / 15$ & $10 / 15$ & $12 / 15$ & $11 / 15$ & $8 / 15$ \\
\hline \multicolumn{2}{|l|}{ Quality } & High & Moderate & Moderate & Moderate & Moderate & Moderate & Low \\
\hline
\end{tabular}

$+=$ fulfilled, $+/-=$ partially fulfilled, $-=$ not fulfilled.

High quality $=13-15$, Moderate quality $=9-12$, Low quality $=0-8$.

there was insufficient evidence to draw conclusions about the association with HBB. ${ }^{1026}$

\section{DISCUSSION}

Included studies in this review addressed intrapartum-related stillbirths and/or one or more subcategories of neonatal mortality in different countries and settings. This systematic review showed that implementing $\mathrm{HBB}$ training and resuscitation method in different low-resource settings is associated with a reduction in perinatal mortality, intrapartum-related stillbirths, 1-day NMR and 7-day NMR, but not for 28-day neonatal mortality. ${ }^{24} 1025282930$.

These findings correspond with other articles and reviews published. Implementation of the HBB training programme and resuscitation method was found to be effective on intrapartumrelated stillbirths and early neonatal mortality in low-resource settings in reviews published by Lee et al, Dempsey et al and Ersdal et al. ${ }^{19} 3031$ Dol et al (2018) reviewed the impact of a Helping Babies Survive (HBS) programme as a whole, that consists of three modules, Essential Care for Every Baby, Essential Care for the Small Baby and HBB. Their results concerning mortality rates and fresh stilbirth rates before and after HBB training suggest the same effects of $\mathrm{HBB}$ as our findings do.

An explanation for the finding that 28-day mortality is not affected by implementation of HBB could be that HBB focuses on interventions in the stimulation of spontaneous breathing directly after birth and less on interventions that target postnatal survival. Asphyxiated babies may survive their first day after resuscitation, but can experience other challenges later in the neonatal period. Neurological sequelae, feeding difficulties and infections could lead to other causes of death, later than the first week. Another explanation could be bias, for in low-resource settings, due to many factors, follow-up is challenging, as reflected in the low numbers of studies that focused on this timeslot. Last, the quality and power of the two studies that did focus on 28-day mortality was suboptimal. Both studies, although large in numbers of patients, seemed underpowered to significantly show smaller differences in mortality, if present.

Where studied, overall NMRs (28 days) did not change after HBB implementation. Additional interventions in the postnatal period that focus on other causes of mortality such as neonatal infections, convulsions, hypothermia and feeding difficulties are probably necessary to increase the overall neonatal survival in low-resource settings. ${ }^{28}$

The strength of this review is the quality appraisal by two researchers. Differences were discussed until consensus was reached; when consensus was not reached, disagreements were discussed in the research group. Only recent studies were included and all studies used similar analysis methods, which led to comparable outcomes. Because of clinical and statistical heterogeneity, we could not perform a meta-analysis of our findings, but the quality of the different included studies was high enough to draw conclusions for each subcategory mentioned.

Several limitations must be acknowledged in this review. First, contamination and cointervention were not addressed in most included studies. It is unclear whether other interventions influenced study outcomes; this could create a risk of performance bias. $^{24-27}$

Second, the sample sizes of two included studies were too small to provide significant results (in subcategories of neonatal mortality), which led to limited conclusions. ${ }^{1026}$

Research studying the association between the introduction of HBB and neonatal mortality is still ongoing. The results of 
Original research

Table 4 Mortality rates and calculated rate ratio

\begin{tabular}{|c|c|c|c|c|c|}
\hline Author & $\begin{array}{l}\text { Mortality rate/1000 } \\
\text { deliveries pre-HBB }\end{array}$ & $\begin{array}{l}\text { Mortality rate/1000 } \\
\text { deliveries post-HBB }\end{array}$ & $95 \% \mathrm{Cl}$ & $P$ value & RR \\
\hline \multicolumn{6}{|c|}{ Mortality rates of deliveries } \\
\hline \multicolumn{6}{|l|}{ Perinatal mortality } \\
\hline Bellad et al & 25.4 & 23.4 & -3.11 to 7.80 & 0.39 & 0.92 \\
\hline Kc et al & 30.9 & 23.3 & - & $<0.001$ & 0.75 \\
\hline \multicolumn{6}{|c|}{ Intrapartum-related stillbirths } \\
\hline Arabi et al & 10.5 & 3.3 & - & 0.003 & 0.31 \\
\hline Bellad et al & 12.5 & 9.5 & -0.21 to 7.70 & 0.06 & 0.76 \\
\hline Goudar et al & 17.2 & 9.2 & 0.37 to 0.78 & $\leq 0.001$ & 0.53 \\
\hline Kc et al & 9.0 & 3.2 & 0.32 to 0.66 & $<0.001$ & 0.36 \\
\hline Mduma et al & 16.0 & 14.5 & - & 0.517 & 0.91 \\
\hline Msemo et al & 19.0 & 14.4 & 0.64 to 0.90 & 0.001 & 0.76 \\
\hline \multicolumn{6}{|c|}{ Mortality rate of live births } \\
\hline \multicolumn{6}{|c|}{ 1-day neonatal mortality } \\
\hline Bellad et al & 19.4 & 18.6 & -3.65 to 5.26 & 0.72 & 0.96 \\
\hline Kc et al & 5.2 & 1.9 & - & $<0.001$ & 0.37 \\
\hline Mduma et al & 11.1 & 7.2 & 0.41 to 0.98 & 0.04 & 0.65 \\
\hline Msemo et al & 13.4 & 7.1 & 0.43 to 0.65 & $<0.0001$ & 0.53 \\
\hline Wrammert et al & 5.5 & 1.9 & - & $<0.01$ & 0.35 \\
\hline \multicolumn{6}{|c|}{ 7-day neonatal mortality } \\
\hline Arabi et al & 13.5 & 4.3 & - & 0.001 & 0.32 \\
\hline Bellad et al & 13.0 & 14.0 & -5.45 to 2.64 & 0.49 & 1.08 \\
\hline Wrammert et al & 9.8 & 7.7 & - & 0.08 & 0.81 \\
\hline \multicolumn{6}{|c|}{ 7-28-day neonatal mortality } \\
\hline Wrammert et al & 3.0 & 4.1 & - & 0.17 & 1.37 \\
\hline \multicolumn{6}{|c|}{ 28-day neonatal mortality } \\
\hline Goudar et al & 18.0 & 19.0 & 0.80 to 1.47 & 0.59 & 1.06 \\
\hline Wrammert et al & 12.8 & 11.7 & - & 0.46 & 0.91 \\
\hline
\end{tabular}

$\mathrm{RR}$, rate ratio.

these studies could give new and possibly more detailed information. ${ }^{83233}$

The HBB intervention on its own seems insufficient for reducing the 28-day NMR. Future research should be expanded to include community care in low-resource settings with adequate follow-up to assess NMRs and causes in the first day, week and month of life. Generating high-quality evidence will require well-designed studies with a broad range of facilities and a large sample size. It is important to prevent a high rate of 'lost to follow-up' when neonates are no longer admitted to neonatal wards. Interventions in every neonatal ward or birth centre that participates in research should be free from performance bias. A protocol for implementing $\mathrm{HBB}$ can be useful for accomplishing that. ${ }^{34}$ The method is preferably taught, refreshed and maintained in a similar high-frequency, low-impact matter.

\section{CONCLUSION}

Implementing $\mathrm{HBB}$ training and resuscitation method is a simple and low-cost intervention. that reduces intrapartum-related stillbirths and early neonatal mortality

The strongest decline was found in intrapartum-related stillbirths and 1-day NMRs mainly declined, most likely because HBB focused on resuscitation interventions directly after birth. The 28-day mortality rate did not change after implementing HBB. Increasing the neonatal survival rate will require additional interventions in the postnatal period that focus on other causes of mortality. Further research is necessary to obtain more detailed information about the association between HBB training and neonatal mortality regarding causes of death for babies that die after initial successful resuscitation.

Correction notice The article type has been changed to Original article since this paper was published Online First.

Acknowledgements Peter Dekkers MSc, for reading and assessing papers in the first phase of this review and Hetty Vonk for editing the manuscript.

Contributors JMDV conceptualised and designed the study, collected data, performed the data search, carried out the analyses and drafted the manuscript. MYK conceptualised the study, performed the second data search and collection, carried out data analysis and designed the manuscript. These both authors contributed equally. KB critically reviewed and revised the manuscript for important intellectual content. WBdV critically reviewed the manuscript and considerably contributed to the editing and revision of this systematic review. HDLO critically reviewed and revised the manuscript on methodological quality and design. AvdH conceptualised and designed the study, coordinated and reviewed the data collection and instruments, reviewed and revised the manuscript. All authors approved the final manuscript as submitted and agree to be accountable for all aspects of the work.

Funding The authors have not declared a specific grant for this research from any funding agency in the public, commercial or not-for-profit sectors.

Competing interests None declared.

Patient consent for publication Not required.

Provenance and peer review Not commissioned; externally peer reviewed.

\section{REFERENCES}

1 Wang H, Coates M, Coggeshall M, et al. GBD 2015 Child Mortality Collaborators. Global, regional, national, and selected subnational levels of stillbirths, neonatal, infant, and under-5 mortality, 1980-2015: a systematic analysis for the Global Burden of Disease Study 2015. Lancet 2016:388:1725-74. 
2 UNICEF. Levels and trends in child mortality: Report 2015 Estimates developed by the UN Inter-agency Group for Child Mortality Estimation. 2015:1-30.

3 Vossius C, Lotto E, Lyanga S, et al. Cost-Effectiveness of the "Helping Babies Breathe" Program in a Missionary Hospital in Rural Tanzania. PLoS One 2014;9:e102080-6.

4 Steele C. Helping babies breathe around the world. J Obstet Gynecol Neonatal Nurs 2013:42:243-6.

5 Wilson A, Gallos ID, Plana N, et al. Effectiveness of strategies incorporating training and support of traditional birth attendants on perinatal and maternal mortality: metaanalysis. BMJ 2011;343:d7102-10.

6 Gülmezoglu AM, Lawrie TA. Impact of training on emergency resuscitation skills: Impact on Millennium Development Goals (MDGs) 4 and 5. Best Pract Res Clin Obstet Gynaecol 2015;29:1119-25.

7 Seto TL, Tabangin ME, Josyula S, et al. Educational outcomes of Helping Babies Breathe training at a community hospital in Honduras. Perspect Med Educ 2015;4:225-32.

8 Ashish KC, Målqvist M, Wrammert J, et al. Implementing a simplified neonatal resuscitation protocol-helping babies breathe at birth (HBB) - at a tertiary level hospital in Nepal for an increased perinatal survival. BMC Pediatr 2012;12:159.

9 World Health Organization. The Global Burden of Disease: 2004 update. WHO 2008:1-146.

10 Goudar SS, Somannavar MS, Clark R, et al. Stillbirth and newborn mortality in India after helping babies breathe training. Pediatrics 2013;131:e344-e352.

11 Wall SN, Lee AC, Niermeyer S, et al. Neonatal resuscitation in low-resource settings: what, who, and how to overcome challenges to scale up? Int I Gynaecol Obstet 2009;107 Suppl 1:S47-S64.

12 Spector JM, Daga S. Preventing those so-called stillbirths. Bull World Health Organ 2008;86:315-6.

13 Flenady V, Wojcieszek A, Ellwood D, et al. Seminars in Fetal \& Neonatal Medicine Classi fi cation of causes and associated conditions for stillbirths and neonatal deaths The International Stillbirth Alliance Collaborative for Improving Classi fi cation of Perinatal. Semin Fetal Neonatal Med 2017;22:176-85.

14 Singhal N, Lockyer J, Fidler H, et al. Helping Babies Breathe: global neonatal resuscitation program development and formative educational evaluation. Resuscitation 2012;83:90-6.

15 Musafili A, Essén B, Baribwira C, et al. Evaluating Helping Babies Breathe: training for healthcare workers at hospitals in Rwanda. Acta Paediatr 2013;102:e34-e38.

16 Bang A, Patel A, Bellad R, et al. Helping Babies Breathe (HBB) training: What happens to knowledge and skills over time? BMC Pregnancy Childbirth 2016;16:364.

17 Ersdal HL, Vossius C, Bayo E, et al. A one-day "Helping Babies Breathe" course improves simulated performance but not clinical management of neonates. Resuscitation 2013;84:1422-7.

18 Seto T, Tabangin M, Taylor K, et al. Breaking Down the Objective Structured Clinical Examination. Simul Healthc J Soc Simul Healthc 2017:1-7.
19 Dempsey E, Pammi M, Ryan A, et al. Standardised formal resuscitation training programmes for reducing mortality and morbidity in newborn infants (Review). Cochrane Database of Systematic Reviews 2015;9:1-69.

20 Dol J, Campbell-Yeo M, Murphy GT, et al. The impact of the Helping Babies Survive program on neonatal outcomes and health provider skills: a systematic review. JBI Database System Rev Implement Rep 2018;16:701-37.

21 Moher D, Liberati A, Tetzlaff J, et al. Systematic Reviews and Meta-Analyses: The PRISMA Statement. PLoS Med 2009;6:e1000097.

22 Proper Kl, Singh AS, van Mechelen W, et al. Sedentary behaviors and health outcomes among adults: a systematic review of prospective studies. Am J Prev Med 2011:40:174-82.

23 Law M, Stewart D, Pollock N, et al. Guidelines for critical review of the literature: Quantitative studies. McMasters Univ 1998:14:1-11.

24 Mduma E, Ersdal H, Svensen E, et al. Frequent brief on-site simulation training and reduction in 24-h neonatal mortality--an educational intervention study. Resuscitation 2015;93:1-7.

25 Msemo G, Massawe A, Mmbando D, et al. Newborn mortality and fresh stillbirth rates in Tanzania after helping babies breathe training. Pediatrics 2013;131:e353-e360.

26 Bellad RM, Bang A, Carlo WA, et al. A pre-post study of a multi-country scale up of resuscitation training of facility birth attendants: does Helping Babies Breathe training save lives? BMC Pregnancy Childbirth 2016;16:222.

27 Kc A, Wrammert J, Clark RB, et al. Reducing Perinatal Mortality in Nepal Using Helping Babies Breathe. Pediatrics 2016;137:e20150117.

28 Wrammert J, Kc A, Ewald U, et al. Improved postnatal care is needed to maintain gains in neonatal survival after the implementation of the Helping Babies Breathe initiative. Acta Paediatr 2017;106:1280-5.

29 Arabi AME, Ibrahim SA, Manar AR, et al. Perinatal outcomes following Helping Babies Breathe training and regular peer-peer skills practice among village midwives in Sudan. Arch Dis Child 2018;103:24-7.

30 Lee AC, Cousens S, Wall SN, et al. Neonatal resuscitation and immediate newborn assessment and stimulation for the prevention of neonatal deaths: a systematic review, meta-analysis and Delphi estimation of mortality effect. BMC Public Health 2011;11(Suppl 3):S12.

31 Ersdal HL, Singhal N. Resuscitation in resource-limited settings. Semin Fetal Neonatal Med 2013;18:373-8.

32 Eblovi DE. Measuring skills retention and impact of helping babies breathe trainings in Ghana. Ann Glob Health 2016;82:385.

33 Bang A, Bellad R, Gisore P, et al. Implementation and evaluation of the Helping Babies Breathe curriculum in three resource limited settings: does Helping Babies Breathe save lives? A study protocol. BMC Pregnancy Childbirth 2014;14:116.

34 American Academy of Paediatrics. Guide for Implementation of Helping Babies Breathe(HBB): Strengthening neonatal resuscitation in suitable programs of essential newborn care. 2011. 